\title{
Editor's Column: The PMLA Editorial Process
}

N MY FIRST COLUMN AS EDITOR OF PMLA (JAN. 2001), I TOLD the membership about the current decline in submissions to the jour-

nal and how it threatened to change the nature of the publication. In the March 2001 issue I summarized the various reasons why submitting work to PMLA is incumbent on all the association's members. In this column I aim to describe the editorial process as a whole, hoping that understanding its several stages may help demystify the prevailing view that it is a forbidding and unnecessarily complex ordeal.

I am aware that describing even the simplest process in detail can make it appear thoroughly complicated - the sort of effect that Rube Goldberg famously put to good use in his drawings of impossible contraptions designed to accomplish the smallest tasks. My desire to demystify the journal's editorial process by detailing its steps could thereby backfire miserably, instilling in the reader an even larger resolve not to submit work to PMLA. My hope is that the reader will keep in mind the fluidity of the process and understand the ensuing description as necessary to render as transparently as I can the movement of a submission through it.

On arrival at the editorial office, each manuscript is assigned by the staff a unique code based on the month, the year, and the submission's order of arrival in the month. Code 15DE01, for instance, would refer to the fifteenth manuscript received in December 2001. The staff refers to the manuscript by this code throughout the editorial process to protect the author's anonymity. A staff member then reviews the manuscript to make sure that there are no textual clues to the author's identity: recognizable personal or professional information, acknowledgments, references to previous work by the author in the first person, and so on. Any such clues are blacked out, again so that the author's identity will not be known throughout the editorial process. The staff also checks that the author is a current

(C) 2OOI BY TIE MODERN LANGUAGE ASSOCLATION OF AMIRICA 
member and that the submission's length falls within the prescribed limits $(2,50)-9,000$ words, including notes).

PMLA's editorial stalf keeps current a large database of potential consultant readers organized by field, period, genre, and the like. Usually a manuscript is sent to a consultant reader who is a specialist in a relevant area. as well as to the member of the journal's Advisory Committee whose specialization matches the manuscript's topic most closely. (The Advisory Committee is chosen by the MLA's Executive Council.) The staff may refer to the MLA Bibliography to identify appropriate readers. The readers' database is a work in progress, and the staff adds to it by incorporating members of division and discussion groups newly elected by the membership, by periodically searching the MLA Bibliography, and by taking suggestions from readers and from other members. Equally important, the database also holds comments on the thoroughness, tone. length, punctuality, and so on of a reader's previous performance(s). The editor and the staff compile this information for every report filed, with the aim of ensuring that all submissions receive the fairest, most thorough, and speediest treatment at this critical step of the evaluation process.

Once the readers are selected, the manuscript is sent first to the specialist reader, who, on completing his or her review, forwards the submission to the Advisory Committee member previously chosen.' A set of instructions sent along with the manuscript asks readers, among other things, to return the submission to the MLA editorial office immediately if they do not feel competent to judge it or if they know the author's identity (fig. 1). The mailing also includes a report form that secks to elicit the kind of comments

Dear ——:

I am writing to ask you to review the enclosed manuscript, which has been sent to $P M L A$ for possible publication. If you are willing to serve as a reviewer for this manuscript, I ask that you return it to us with your evaluation no later than —- Please return it to us immediately (using the enclosed envelope) if (a) you cannot read it by that date, (b) you know the identity of the author, or (c) you decide you are not an appropriate reader for this manuscript.

In reviewing the article, please consider whether it meets the criteria in the statement of editorial policy (a copy of which is enclosed), provides appropriate bibliographical support, and makes an original argument that has importance for the field you work in. Authors receive a copy of your comments; your advice can be very useful to them in revising their articles. Articles that receive two votes for publication will be reviewed by the PMLA Editorial Board, which will carefully weigh your comments as it makes a final decision.

FIG. 1

This letter is accompanied by the statement of yitorial policy that appears in the ont of each issue of PMLA. If the submission is on a special topic the topic announcement is also enclosed.
On behalf of the editor and the members of the editorial board, I would like to thank you for the time and effort you will spend reviewing this article. The contributions of readers like you provide an important professional service to authors and enhance $P M L A$ 's reputation. If you have questions, about the process or about your role as a reader, I hope you will get in touch with me.

With best wishes,

$$
\begin{aligned}
& \text { Judy Goulding } \\
& \text { Managing Editor } \\
& \text { MLA Publications }
\end{aligned}
$$

PS If you are unable to read the article, we would be grateful if you would suggest other possibilities for readers. 
Reader's Report

DATE

TITLE

D PUBLISHABLE; RECOMMENDED TO THE EDITORIAL BOARD (no serious qualifications; minor revisions may be called for) Please explain why this article should appear in PMLA.

D Potentialiy Publishabi.f. after Revisions

Please provide specific suggestions for revision.

$\square$ Should be returned to reader after revisions

$\checkmark$ Could go directly to the Editorial Board after revisions

$\square$ DECLINE

Please include suggestions for revising the article.

$\square$ Check here if you wish to remain anonymous

NAME

most useful to the author and the board (fig. 2). Readers are finally asked to submit their reports within a month of receiving the manuscript. Reports can range from extensive and breathtakingly thorough to perfunctory and dismissive. The latter kind are few and far between, in my experience, although that may be small comfort to the rare authors whose manuscripts receive such superficial treatment. Indeed, the vast majority of readers take their task extremely conscientiously, and the reports they produce are serious, detailed, and full of suggestions for revisions, even when the piece is judged to be of superior quality.

After the editorial office receives the two reports, the next step is determined by their combined recommendations. A little-known fact about PMLA's editorial process is that no one person can dictate the final disposition of a submission. Two votes are required for an article to be declined or to advance to the consideration of the Editorial Board. If the reports do not produce a clear consensus, the manuscript is sent to a third reader, whose report casts the deciding vote. If the readers estimate that the submission might be recommended to the board once revisions they suggest are undertaken successfully, the author is sent the reports and is given the opportunity to revise the text. In such cases, the reworked manuscript is sent back to one of the original readers, who decides whether to recommend that the piece be submitted to the consideration of the Editorial Board. When two readers recommend against publication, the manuscript is returned to the author along with copies of all reports generated by the process. Since readers are given the option to recommend that a manuscript deemed promising be returned to the author for revision and resubmission, it is the 
journal's policy not to accept resubmission of essays that have been declined.

Whenever two readers recommend that a manuscript be published, it is evaluated next by the Editorial Board. Often, before the submission is forwarded to the board, it is sent back to the author with copies of the reports. This practice allows authors to consider revisions the readers recommended-substantive, stylistic, bibliographic, and so on-and to present the most finished and complete version of their work to the board.

The Editorial Board of PMLA is chosen by the association's Executive Council, and it consists of six members, who serve for two years, as well as the editor, who is appointed by the Executive Council to a three-year term. Terms are staggered, so that at the first meeting of each year (in October) there are always three new members. The board meets three times a year for two days- in October, February, and Mayat the MLA offices in New York. By representing a variety of fields, areas of specialization. and critical approaches, the board functions as a microcosm of the profession.

Most, though not all, of the board's time is spent in the evaluation of submissions forwarded to it by readers. The number of articles considered at a meeting may range from fifteen or so to around twenty-five. Every member reads all the articles under consideration and composes for each a written summary of what in his or her mind are the submission's strengths and shortcomings. At the meeting the discussion of each text is a truly democratic exercise: the seven members take turns offering their judgments to the rest of the group, after which there is a discussion to address differences of opinion that may have surfaced. The board seeks consensus, and when members disagree, most of the time compromises can be arrived at through requests for revisions or outright conditions placed on acceptances. Indeed, only once in my three years on the board - two years as regular member and one as editor-has a sub- mission aroused such vehemently divergent reactions that adjudication on it required a straight in-or-out voice vote.

I have never heard a current or former member complain about his or her tour of duty on the board, in spite of all the work it entails. The board's discussions are one of those experiences that remind you fully why at some point you chose the so-called life of the mind. Imagine, if you will, two intense days of exchanges with six other scholars (all of whom you respect and even admire) who have read all the texts under discussion and have thought deeply about the issues they address. No departmental polilics, no posturing, no partis pris; instead, an oasis of intellectual exchange undertaken in the most respectful and considerate fashion and in which each work receives total and sustained attention. Although it is true that the board is not shy about declining articles, it is also true that members sometimes spend considerable time discussing what is necessary to improve even a declined manuscript.

There are a number of possible outcomes of the board's deliberations. First, a submission can be accepted or declined outright for publication. Second, a manuscript can be accepted on the condition that the author revise it to address issues about which the board has concern. Third, when a submission is not acceptable but has great potential, the board can invite the author to submit a revised version for consideration at a subsequent meeting. Only after a final decision to publish or decline a submission has been reached is the board told the author's identity by the managing editor, who is the only person at the meeting with this information and who does not participate directly in the discussion.

The editorial staff and the editor keep detailed notes of the board's exchanges on all submissions. During the week following the meeting, each author is sent a letter that reports the outcome and summarizes the comments board members made in their discussion of the essay. Authors sometimes write back requesting clarification of 
the board's discussion; the editor handles such requests. The authors of accepted manuscripts are asked to compose abstracts of their articles and, if the board has suggestions for changes, are given deadlines for the final versions.

When an author returns the final version of an accepted article to the editorial office, it is forwarded to the copyediting department. PMLA's copyediting operation provides care and thoroughness that are rare in scholarly publishing today. The author receives back from this department a hard copy of the manuscript that often has a considerable number of suggestions and queries. Some authors are put off by this level of scrutiny, but, at least in my experience, the initial dismay soon gives way to a feeling of respect for the professionalism clearly in evidence and finally to gratitude that someone should have taken that amount of care and time to improve your work. Authors later receive galley proofs for their inspection as well. At present, the time between acceptance of an article and its appearance in print is less than one year.

The most significant difference between $P M L A$ 's editorial process and that followed by other, equally prestigious journals is that after readers recommend publication in PMLA, a submission still has to pass muster with the journal's Editorial Board. Since this extra step is dictated by $P M L A$ 's particular status as the journal of an association that serves diverse fields and constituencies, I hazard that this element of the procedure will not be dispensed with any- time soon. On the other hand-and precisely on account of that status-no other journal has the staff and the resources to monitor closely and expedite a submission's movement through the editorial process as efficiently as PMLA. Hence, I would argue that any delay associated with the review by the Editorial Board is offset by the watchful overseeing that accompanies a manuscript submitted to $P M L A$ every step of the way.

Since I became editor, Judy Goulding (PMLA's managing editor) and I have been reviewing all aspects of the editorial process to identify ways of making it more efficient and responsive. But a journal earns the trust of those who submit their work to it--to paraphrase the advertisement campaign of a leading American brokerage firm - one author at a time. Therefore, if you recently submitted work to PMLA and the process as described above faltered at some point, I encourage you to write to either one of us at the journal's office. Since PMLA will apply the most exacting scholarly standards to your submission, it is only fair that PMLA be judged in turn against your highest editorial expectations.

Carlos J. Alonso

\section{Note}

${ }^{1}$ The journal is currently experimenting with a variation of this procedure that allows for faster reporting: manuscripts now are sent simultaneously to both readers. 